\title{
Inter-Pulse Interval Between Rectangular Voltage Pulses Affects Electroporation Threshold of Artificial Lipid Bilayers
}

\author{
Alenka Maček Lebar, Gregory C. Troiano, Leslie Tung, and Damijan Miklavčič*
}

\begin{abstract}
This paper describes experiments that determine how the inter-pulse interval between rectangular pulses in a train of pulses alters the threshold of electroporation of 1-pamitoyl 2-oleoyl phosphatidycholine bilayer lipid membranes. The bilayers were exposed to a train of sixteen $100-\mu$ s duration pulses. Threshold voltage and the sequence number of the pulse in the train, where onset of the electroporation occurred, were recorded for six inter-pulse intervals ( $\infty, 1000 \mu \mathrm{s}, 100 \mu \mathrm{s}, 10 \mu \mathrm{s}, 1 \mu \mathrm{s}, 0 \mu \mathrm{s})$. The threshold voltage of the pulse train decreased linearly with the logarithm of the inter-pulse interval. When the inter-pulse interval was $1 \mu \mathrm{m}$, electroporation threshold dropped to that of a single pulse with duration $1600 \mu$ s (equal to the sum of all pulse durations in the train). In this case, the occurrence of bilayer rupture was almost equally frequent for all pulses in the train. When the inter-pulse interval between the pulses exceeded $1 \mu \mathrm{s}$, the influence of the previous pulse on the response to the following pulse declined. It became more likely that the bilayer ruptured during the first half of the train. These experimental observations suggest that a train of pulses applied with short inter-pulse interval (less than $1 \mathrm{~ms}$ ) can lower the electroporation threshold of bilayer lipid membranes.
\end{abstract}

Index Terms-Bilayer lipid membrane, electroporation, frequency, threshold voltage.

\section{INTRODUCTION}

$\mathbf{T}$ HE application of strong electric pulses to the plasma membrane results in a considerable increase in its permeability and conductance. This phenomenon is named electroporation, according to the most widely accepted theory alleging that the pore-like structures are created in the plasma membrane. Since one of the consequences is increased permeability of the plasma membrane, the term "electropermeabilization" is also used. Several theoretical models have been proposed to describe the physical basis of electroporation, but none perfectly describes all of the features of the phenomenon [1]-[5]. The molecular mechanisms of electroporation are still

Manuscript received August 6, 2002; revised December 30, 2002. This work was supported through the summer student exchange program between the Whiting School of Engineering, The Johns Hopkins University, and the University of Ljubljana. Asterisk indicates corresponding author.

A. Maček Lebar is with the University of Ljubljana, Faculty of Electrical Engineering, SI-1000 Ljubljana, Slovenia.

G. C. Troiano was with the Johns Hopkins University, Baltimore, MD 21205

USA. He is now with Alkermes Inc., Boston, MA 02139 USA.

L. Tung is with the Johns Hopkins University, Department of Biomedical Engineering, Baltimore, MD 21205 USA.

*D. Miklavčič is with the University of Ljubljana, Faculty of Electrical Engineering, SI-1000 Ljubljana, Slovenia (e-mail: damijan@svarun.fe.uni-lj.si).

Digital Object Identifier 10.1109/TNB.2003.809464 unclear and under discussion because of lack of experimental data on the initial stages of pore formation as well as direct visualization of the pore. On the other hand, experimental observations on model systems of biological membranes, such as lipid bilayer membranes, lipid vesicles, cells, and tissue from laboratory animals, have suggested many directions for manipulative applications in cell biology and medicine [1], [6]-[8].

Electroporation is either reversible or irreversible, depending on the electrical parameters chosen. Reversible electroporation can be used for introducing biologically active compounds into living cells [9]. Nowadays, it is routinely used for the introduction of macromolecules into living cells in vitro and is a basis for electrofusion used to produce hybridoma cells [10]. Gene therapy, which has already found applications in the treatment of cancer [11] and muscle disorders [12], [13], is efficiently performed by electric pulses. Electroporation holds promise in transdermal drug delivery [14] and has been successfully used to deliver DNA even to cardiac muscle [15]. A promising medical application is tissue permeabilization, which can be used in electrochemotherapy to increase the efficiency of antitumoral drugs [16]-[19]. Irreversible electroporation is an emerging technology of nonthermal food preservation [20], [21].

Efficiency of the applications previously mentioned depends on several parameters. Type of cells; their size, shape, membrane structure, and composition; transmembrane potential; growth stage; pulsing buffer; and electrode material are of great importance for in vitro applications [22]-[27]. Electrical parameters like voltage applied, pulse duration, number of pulses, pulse frequency, and pulse shape are the major factors that strongly affect both in vitro [6], [7], [28] and in vivo techniques [12], [15]. Investigations have also shown that electrode geometry [16], [29] has an influence on the medical and biological applications of electroporation.

Therapy as a medical application should be maximally effective, with minimal side effects and pain to the patient. Nerve stimulation is one of the undesirable side effects of electrochemotherapy, and causes contractions of surrounding muscles, which are unpleasant [17], [18]. If electroporation can be effective at frequencies that do not stimulate nerves, electrochemotherapy and other electroporation-based medical applications will be more acceptable to patients. Therefore, special effort should be made on optimizing electrical treatment parameters: voltage applied, pulse duration, pulse shape, 
number of pulses, and pulse-repetition frequency. At the same time, the electrical waveforms should be effective, safe, and technically easy to generate.

Numerous studies have shown how applied voltage, pulse duration, and number of pulses influence membrane electroporation [6], [7], [12], [30]. In almost all studies where trains of pulses were used, the pulse-repetition frequency was $1 \mathrm{~Hz}$. The fact that generation of high-voltage pulses with high repetition rate is technically difficult could be the reason for the limited numbers of studies dealing with pulse-repetition frequency [31]. Until now, only a few studies have experimentally demonstrated that pulse frequency can modulate cell viability and electropermabilization efficiency in in vitro experiments [30], [32], [33]. Although trains of pulses (four or eight) give better results than a single pulse in many biological and medical applications of electroporation, the influence of the previous pulse on the following one is still under investigation [8], [34], [35].

In this paper, we determined the threshold of electroporation of 1-pamitoyl 2-oleoyl phosphatidycholine (POPC) lipid bilayer membranes which were exposed to trains of rectangular pulses. The main question that we addressed was how the interval between pulses in the train affects the threshold of electroporation. Our experimental results reveal that the threshold of electroporation decreases with shorter inter-pulse interval.

\section{MATERIALS AND MeTHODS}

Artificial lipid bilayers made of synthetic lipid POPC (Avanti Polar Lipids, Alabaster, AL, powder form) dissolved in a 9:1 mixture of hexane and ethanol $(10 \mathrm{mg} / \mathrm{ml})$ were investigated. Bilayers were formed by the folding method across a circular hole (105 $\mu \mathrm{m}$ in diameter) in a Teflon sheet $(25-\mu \mathrm{m}$ thick). Teflon chamber and protocol described previously by Troiano et al. [36] was used. The Teflon chamber was filled with electrolyte $(100 \mathrm{mM} \mathrm{KCl}, 10 \mathrm{mM}$ Hepes, $\mathrm{pH}$ 7.40) prepared using deionized water. Four electrodes $(\mathrm{Ag}-\mathrm{AgCl}$, In Vivo Metric, Healdsburg, CA) for the stimuli and measurements of current and voltage were simply submerged in the salt solution. One side of the hole in the Teflon sheet was treated with $1 \mu \mathrm{l}$ of lipid solution. After the evaporation of the solvent, both sides of the hole were treated with $1.5 \mu \mathrm{l}$ of hexadecane (30\% in pentane). A drop of $2 \mu \mathrm{l}$ of the lipid solution was deposited on each side of the chamber and allowed to spread over the aqueous-air interface for at least $20 \mathrm{~min}$. To form a bilayer, the solution level in both compartments was carefully raised to the same height just above the hole. After a bilayer was irreversibly electroporated, a new bilayer was formed by lowering the solution levels below the hole, and then raising them above the hole again. All experiments were performed at $18{ }^{\circ} \mathrm{C}$ room temperature.

The experimental setup for measurement of the bilayer capacitance $\left(C_{m}\right)$ was described previously by Sharma et al. [37]. The charge pulse method was used to determine the stray capacitance of the system, i.e., of the circuitry, chamber, and sheet $\left(C_{s}\right)$. The system was pulsed for $10 \mu$ s with a subthreshold pulse of $300 \mathrm{mV}$. $C_{s}$ was calculated from the time constant of the voltage discharge through an external resistor. The membrane capacitance $\left(C_{m}\right)$ was calculated by subtracting $C_{s}$ from the total capacitance $\left(C_{\mathrm{t}}\right)$, which was measured in the same manner
TABLE I

SPECIFIC CAPACITANCES AND THRESHOLD VOLTAGES FOR BILAYERS EXPOSED TO TRAINS OF 16 PULSES WITH DIFFERENT INTER-PULSE INTERVALS. Values Given Are MeAn \pm Standard DEVIaTion

\begin{tabular}{ccc}
\hline $\begin{array}{c}\text { Inter-pulse interval } \\
(\mu \mathrm{s})\end{array}$ & $\begin{array}{c}\text { Specific lipid } \\
\text { bilayer capacitance } \\
\left(\mu \mathrm{F} / \mathrm{cm}^{2}\right)\end{array}$ & Threshold voltage \\
\hline 0 & $0,54 \pm 0,10$ & $334 \pm 21$ \\
1 & $0,55 \pm 0,12$ & $345 \pm 16$ \\
10 & $0.52 \pm 0,10$ & $377 \pm 16$ \\
100 & $0,52 \pm 0,10$ & $402 \pm 24$ \\
1000 & $0,50 \pm 0,05$ & $420 \pm 23$ \\
$\mathrm{INF}$ & $0,60 \pm 0,11$ & $441 \pm 23$ \\
\hline
\end{tabular}

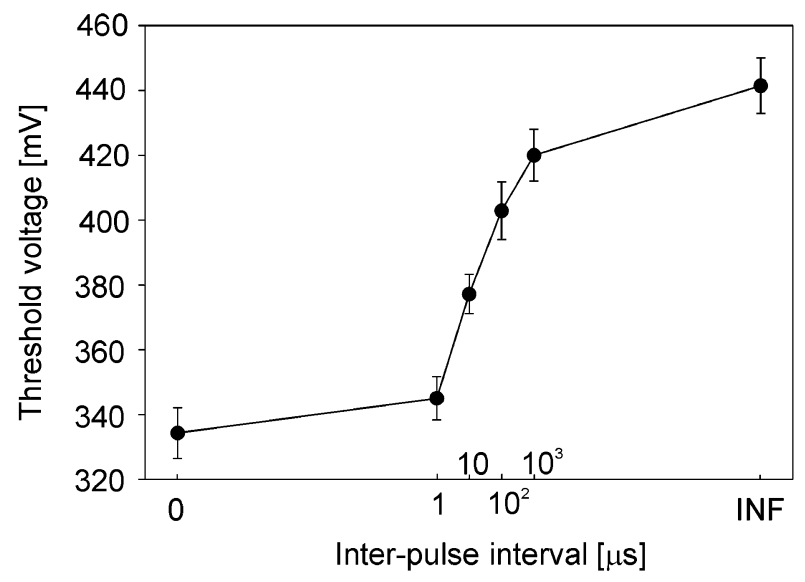

Fig. 1. Dependence of electroporation threshold on the interval between pulses. The error bars in the electroporation threshold represent standard deviations of the data.

as $C_{s}$, but $5 \mathrm{~min}$ after bilayer formation. The bilayer surface area $\left(A_{m}\right)$ was assumed to encompass only $90 \%$ of the area of the hole, with the remaining $10 \%$ consisting of a torus of hexadecane that was necessary to support the bilayer. The specific membrane capacitance $\left(C_{\mathrm{sp}}\right)$ was obtained by dividing $C_{m}$ by $A_{m}$. Obtaining similar values of specific bilayer capacitance was a measure for reproducibility of bilayers.

The irreversible electroporation of the bilayers was studied by the voltage clamp method. The bilayers were exposed to a train of 16 pulses. Each pulse in the train had duration of $100 \mu \mathrm{s}$. The interval between pulses was varied between $1 \mu \mathrm{s}$ and $1000 \mu \mathrm{s}$ by factors of ten. In addition, a single $100 \mu$ s pulse was used to approximate for 16 pulses set infinitely apart, and a single $1600 \mu$ s pulse was used for 16 concatenated pulses (inter-pulse interval of $0 \mu \mathrm{s}$ ). The amplitude of all the pulses in the train was incremented in steps of $10 \mathrm{mV}$ from an initial subthreshold value until electroporation occurred. When electroporation occurred, the transbilayer current increased by several orders in magnitude. For each experiment, we recorded the inter-pulse interval, the sequence number of the pulse in the train where sudden increase of the current was observed, and the electroporation threshold voltage. 

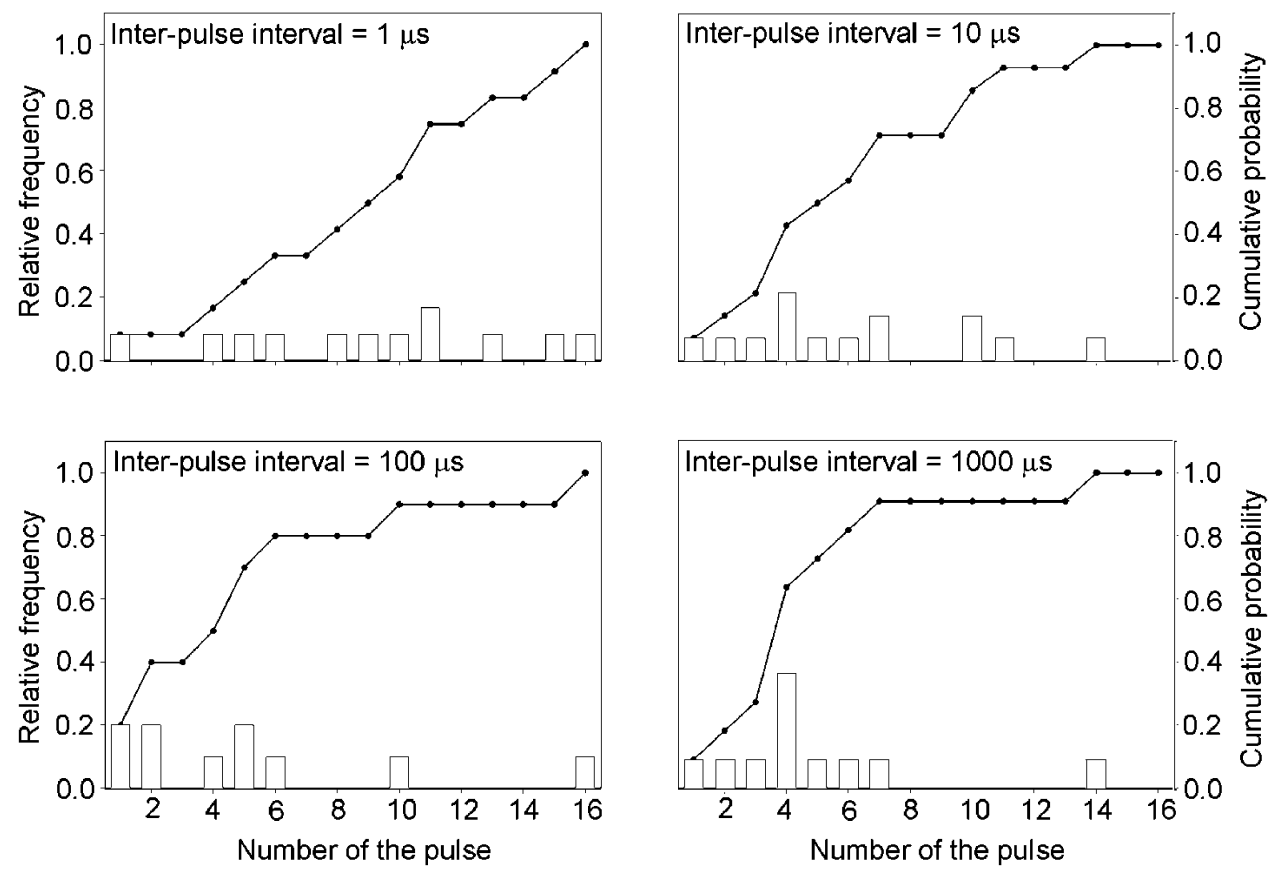

Fig. 2. Relative frequency (bar chart) of bilayer electroporation for each pulse in the train of 16 pulses, and the cumulative probability function. Intervals between pulses lasted $1,10,100$, and $1000 \mu \mathrm{s}$.

Electroporation threshold, specific bilayer capacitance, and the sequence number of the pulse were determined for at least eight bilayers for each inter-pulse interval $(0 \mu \mathrm{s}, 1 \mu \mathrm{s}, 10 \mu \mathrm{s}$, $100 \mu \mathrm{s}, 1000 \mu \mathrm{s}, \infty)$. The statistical significance of changes in threshold voltage for different inter-pulse intervals was determined using the nonparametric Mann-Whitney test. The $\mathrm{p}$ values of less than 0.05 were considered significant for rejection of the null hypothesis.

\section{RESULTS}

Mean threshold voltages $\left(V_{\mathrm{th}}\right)$ and mean specific bilayer capacitances $\left(C_{\mathrm{sp}}\right)$ with their standard deviations are given in Table 1 as a function of the inter-pulse interval. There was no statistical difference between $C_{\mathrm{sp}}$ in different experimental groups. The $C_{\mathrm{sp}}$ for all bilayers included in the study was measured to be $0.54 \pm 0.09 \mu \mathrm{F} / \mathrm{cm}^{2} . V_{\mathrm{th}}$ increased with increasing inter-pulse interval. $V_{\text {th }}$ for an inter-pulse interval of $0 \mu \mathrm{s}$ was $334 \mathrm{mV}$, comparable to $V_{\mathrm{th}}$ for an inter-pulse interval of $1 \mu \mathrm{s}$, which was $345 \mathrm{mV}$. However, $V_{\mathrm{th}}$ for an inter-pulse interval of $10 \mu$ s was $377 \mathrm{mV}$, a value significantly different from the previous two $(p<0.05)$. $V_{\text {th }}$ for an infinite inter-pulse interval was $441 \mathrm{mV}$, a value is higher but not statistically significant $(p>0.1)$ than $V_{\mathrm{th}}$ for the inter-pulse interval of $1000 \mu \mathrm{s}$ $(420 \mathrm{mV})$. The data are also presented in graphical form (see Fig. 1). On the semilog plot, $V_{\text {th }}$ increases nearly linearly with increasing inter-pulse interval over the range of 1 to $1000 \mu \mathrm{s}$.

We also recorded at which pulse in the pulse train electroporation occurred. Fig. 2 shows the relative frequency of bilayer electroporation for each pulse in the train, for different inter-pulse intervals. Also shown in each plot is the cumulative probability function for electroporation in the train, obtained as the running sum of the frequencies of the individual pulses.

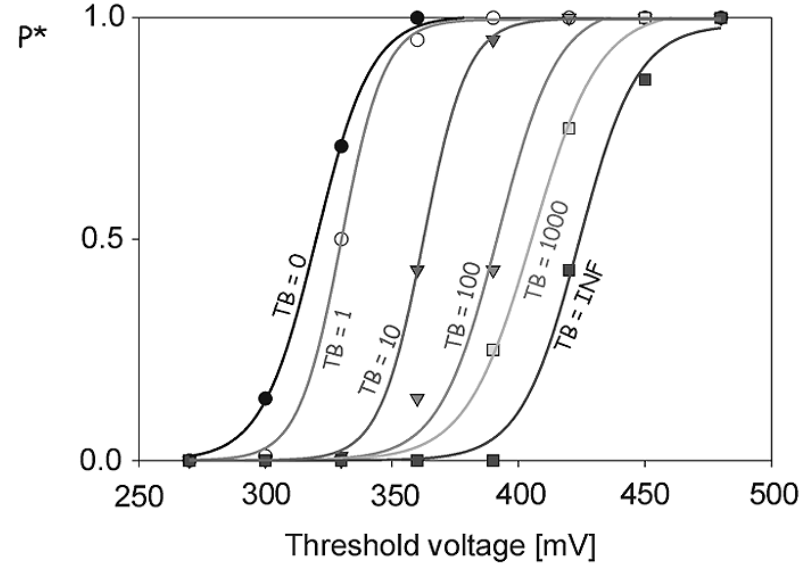

Fig. 3. Probability of bilayer electroporation $\left(P^{*}\right)$ as a function of threshold voltage for various intervals between pulses $T B(\mu \mathrm{s})$.

When the inter-pulse interval was $1 \mu \mathrm{s}$, electroporation occurred with an equal probability throughout the train. The cumulative probability of electroporation increased linearly with the pulse number and attained $90 \%$ at the 15 th pulse. As the inter-pulse interval became longer $(10$ and $100 \mu \mathrm{s})$, it was more likely that the bilayer electroporated during the first half of the train. The cumulative probability of bilayer electroporation reached $90 \%$ at the 11th pulse for an inter-pulse interval of $10 \mu$ s and at the tenth pulse for an inter-pulse interval of $100 \mu \mathrm{s}$. When the inter-pulse interval was $1000 \mu \mathrm{s}$, the probability of bilayer electroporation increased sharply during first four pulses and reached $90 \%$ at the seventh pulse.

In Fig. 3 the probability of bilayer electroporation is presented as a function of threshold voltage for all six inter-pulse intervals. The shapes of the probability curves are all sigmoidal. 


\section{DISCUSSION AND CONCLUSION}

The process of electroporation of lipid bilayer membranes is typically described either by mean lifetime at a given voltage or by electroporation threshold at a given pulse duration. In the former case, voltage amplitude is selected and the bilayer is held at that value until membrane electroporation occurs [38]. All studies consistently report a decline in latency time with an increase in pulse amplitude. In the latter case, the pulse duration is selected and the voltage amplitude is incremented in steps until electroporation takes place. Electroporation voltage thresholds generally decrease linearly with the logarithm of stimulus duration [36]. In practical applications of electroporation, the duration of stimulus is known a priori. Hence, the latter protocol is more informative; therefore, it served as the motivation for our present work.

In earlier studies, Chernomordik et al. [8] and Melikov et al. [34] presented experimental evidence for an influence of the interval between two consecutive voltage pulses on conductance behavior during the second pulse. In both reports, reversible electroporation was studied. Chernomordik et al. [8] compared the current responses of the second pulse for different interpulse intervals. The current oscillogram was identical when the interval between pulses was longer than $1 \mathrm{~s}$ for both lipid and cell membranes. For shorter inter-pulse intervals, the current oscillogram appeared to be a continuation of the current response to the first pulse. They estimated the characteristic times of "healing" the pores created during reversible electroporation to be in the order of some seconds or even minutes. Melikov et al. [34] did similar experiments on lipid bilayer membranes. For inter-pulse intervals shorter than $250 \mathrm{~ms}$, the second pulse resulted in an immediate jump in membrane conductance, while for longer inter-pulse intervals, the conductance behavior was similar to that of the first pulse, i.e., a lag time was observed in the beginning of the second pulse before the membrane conductance was increased.

In our study, we analyzed the influence of the inter-pulse interval on the voltage threshold for irreversible electroporation of lipid bilayer membranes. If the inter-pulse intervals between 16 consecutive pulses were $1 \mu \mathrm{s}$, the electroporation threshold did not differ statistically from the electroporation threshold of a single pulse with duration equal to the sum of durations of all pulses in the train, i.e., $1600 \mu$ s. Furthermore, the occurrence of bilayer electroporation was almost equally likely for all pulses in the train, which is consistent with observation that bilayer lifetime at given voltage is distributed over a rather wide interval [38]. When the interval between pulses in the train exceeded $1 \mu \mathrm{s}$, the influence of the previous pulse on the following pulse diminished. The electroporation threshold of the train of pulses increased linearly with the logarithm of inter-pulse interval over the range of 1 to $1000 \mu$ s (see Fig. 1). In addition, the bilayer was more likely to be electroporated during the first half of the train.

The theoretical model proposed by Joshi and Schoenbach [3] is in line with our experimental study. They used a time-dependent numerical model based on the Smoluchowski equation to simulate pore kinetics and an equivalent circuit representation to determine the transmembrane potential. Their simula- tion suggests that irreversible breakdown is a consequence of the formation of a few large pores. The pore generation rate depends exponentially on the membrane voltage. Therefore, the number of pores is higher and the radius of the pores is larger if the voltage applied across the membrane is higher. It follows that if a subsequent voltage pulse were to be applied before the pores have a chance to fully recover to their prepulse, equilibrium values, then a much shorter pulse duration (or lower pulse voltage) would be required for electroporation of the membrane by the subsequent pulse, compared with an electroporating pulse that lacked a preconditioning pulse. The theoretical model mentioned is a good explanation for the existence of the "prepore" state reported by Melikov et al. [34], and the memory effect presented in the theoretical model is consistent with our experimental observations.

\section{REFERENCES}

[1] E. Neumann, S. Kakorin, and K. Toensing, "Fundamentals of electroporative delivery of drugs and gens (mini-review)," Bioelectrochem. Bioenerg., vol. 48, pp. 3-16, 1999.

[2] J. C. Weaver and Y. A. Chizmadzhev, "Theory of electroporation: a review," Bioelectrochem. Bioenerg., vol. 41, pp. 135-160, 1996.

[3] R. P. Joshi and K. H. Schoenbach, "Electroporation dynamics in biological cells subjected to ultrafast electrical pulses: a numerical simulation study," Phys. Rev. E, vol. 62, pp. 1025-1033, 2000.

[4] J. C. Neu and W. Krassowska, "Asymptotic model of electroporation," Phys. Rev. E, vol. 59, pp. 3471-3482, 1999.

[5] C. Maldarelli and K. Stebe, "An anisotropic, elastomechanical instability theory for electropermeabilization of bilayer-lipid membranes," in Electrical Trauma: The Pathophysiology, Manifestations, and Clinical Management, R. C. Lee, E. G. Cravalho, and J. F. Burke, Eds. Cambridge, U.K.: Cambridge Univ. Press, 1992, pp. 327-360.

[6] H. Wolf, M. P. Rols, E. Boldt, E. Neumann, and J. Teissie, "Control by pulse parameters of electric field-mediated gene transfer in mammalian cells," Biophys. J., vol. 66, pp. 524-531, 1994.

[7] M. P. Rols and J. Teissie, "Electropermeabilization of mammalian cells to macromolecules: control by pulse duration," Biophys. J., vol. 75, pp. $1415-1423,1998$.

[8] L. V. Chernomordik, S. I. Sukharev, S. V. Popov, V. F. Pastushenko, A V. Sokirko, I. G. Abidor, and Y. A. Chizmadzhev, "The electrical breakdown of cell and lipid membranes: the similarity of phenomenologies," Biochim. Biophys. Acta, vol. 902, pp. 360-373, 1987.

[9] L. M. Mir, "Therapeutic perspectives of in vivo cell electropermeabilization," Bioelectrochemistry, vol. 53, pp. 1-10, 2000.

[10] E. Neumann, A. E. Sowers, and C. A. Jordan, Electroporation and Elec trofusion in Cell Biology. New York: Plenum Press, 1989.

[11] M. P. Rols, C. Delteil, M. Golzio, P. Dumond, S. Cros, and J. Teissie, "In vivo electrically mediated protein and gene transfer in murine melanoma," Nature Biotechnol., vol. 16, pp. 168-171, 1998.

[12] L. M. Mir, M. F. Bureau, R. Rangara, B. Schwartz, and D. Scherman, "Long-term, high level in vivo gene expression after electric pulse-mediated gene transfer into skeletal muscle," Comptes rendus acad. sci. Paris, Sciences de la vie, vol. 321, pp. 893-899, 1998.

[13] L. M. Mir, M. F. Bureau, J. Gehl, R. Rangara, D. Rouy, J. M. Caillaud, P. Delaere, D. Branellec, B. Schwartz, and D. Scherman, "High-efficiency gene transfer into skeletal muscle mediated by electric pulses," Proc. Nat. Acad. Sci. USA, vol. 96, pp. 4262-4267, 1999.

[14] M. R. Prausnitz, V. G. Bose, R. Langer, and J. C. Weaver, "Electroporationof mammalian skin: a mechanism to enhance transdermal drug delivery," Proc. Nat. Acad. Sci. USA, vol. 90, pp. 10 504-10 508, 1993.

[15] R. L. Harrison, B. J. Byrne, and L. Tung, "Electroporation-mediated gene transfer in cardiac tissue," FEBS Lett., vol. 435, pp. 1-5, 1998.

[16] R. Heller, R. Gilbert, and M. J. Jaroszeski, "Clinical applications of electrochemotherapy,” Adv. Drug Deliv. Rev., vol. 35, pp. 119-129, 1999.

[17] L. Mir, L. F. Glass, G. Serša, J. Teissie, C. Domenge, D. Miklavčič, M. J. Jaroszeski, S. Orlowski, D. S. Reintgen, Z. Rudolf, M. Belehradek, R. Gilbert, M.-P. Rols, J. Belehradek Jr, J. M. Bachaud, R. DeConti, B. Štabuc, M. C Čemazcaron;ar, P. Coninx, and R. Heller, "Effective treatment of cutaneous and subcutaneous malignant tumors by Electrochemotherapy," Br. J. Cancer, vol. 77, pp. 2336-2342, 1998. 
[18] G. Serša, B. Štabuc, M. C. Čemažar, B. Jančar, D. Miklavčič, and Z. Rudolf, "Electrochemotherapy with cisplatin: potentiation of local cisplatin antitumor effectiveness by application of electric pulses in cancer patients," Eur. J. Cancer, vol. 34, pp. 1213-1218, 1998.

[19] G. Serša, T. Čufer, M. Čemažar, D. Miklavčič, M. Reberšek, and Z. Rudolf, "Electrochemotherapy with bleomycin in the treatment of hypernephroma metastasis: case report and literature review," Tumori, vol. 86 , pp. $163-165,2000$

[20] S. Jeyamkondan, D. S. Jayas, and R. A. Holley, "Pulsed electric field processing of foods: a review," J. Food Prot., vol. 62, pp. 1088-1096, 1999.

[21] N. J. Rowan, S. J. MacGregor, J. G. Anderson, R. A. Fouracre, and O. Farish, "Pulsed electric field inactivation of diarrhoeagenic Bacillus cereus through irreversible electroporation," Lett. Appl. Microbiol., vol. 31 , pp. 110-114, 2000.

[22] T. Tomov and I. Tsoneva, "Are the stainless steel electrodes inert?," Bioelectrochemistry, vol. 51, pp. 207-209, 2000

[23] T. Kotnik, D. Miklavčič, and L. M. Mir, "Cell membrane electropermeabilization by symmetrical bipolar rectangular pulses. Part II. Reduced electrolytic contamination," Bioelectrochemistry, vol. 54, pp. 91-95, 2001.

[24] C. S. Djuzenova, U. Zimmermann, H. Frank, V. L. Sukhorukov, E. Richter, and G. Fuhr, "Effect of medium conductivity and composition of the uptake of propidium iodide into electropermeabilized myeloma cells," Biochim. Biophys. Acta, vol. 1284, pp. 143-152, 1996.

[25] G. Pucihar, T. Kotnik, M. Kandušer, and D. Miklavčič, "The influence of medium conductivity on electropermeabilization and survival of cells in vitro," Bioelectrochemistry, vol. 54, pp. 107-115, 2001.

[26] T. Kotnik, F. Bobanović, and D. Miklavčič, "Sensitivity of transmembrane voltage induced by applied electric fields-a theoretical analysis," Bioelectrochem. Bioenerg., vol. 43, pp. 285-291, 1997.

[27] M. Čemažar, T. Jarm, D. Miklavčič, A. Maček Lebar, A. Ihan, N. A. Kopitar, and G. Serša, "Effect of electric-field intensity on electropermeabilization and electrosensitivity of various tumor-cell lines in vitro," Electro. Magnetobiol., vol. 17, pp. 263-272, 1998.

[28] T. Kotnik, L. M. Mir, K. Flisar, M. Puc, and D. Miklavčič, "Cell membrane electropermeabilization by symmetrical bipolar rectangular pulses. Part I. Increased efficiency of permeabilization," Bioelectrochemistry, vol. 54, pp. 83-90, 2001.

[29] D. Miklavčič, K. Beravs, D. Šemrov, M. Čemažar, F. Demšar, and G. Sersa, "The importance of electric field distribution for effective in vivo electroporation of tissues," Biophys. J., vol. 74, pp. 2152-2158, 1998.

[30] M. C. Vernhes, P. A. Cabanes, and J. Teissie, "Chinese hamster ovary cells sensitivity to localized electrical stresses," Bioelectrochem. Bioenerg., vol. 48, pp. 17-25, 1999.

[31] M. Puc, S. Reberšek, and D. Miklavčič, "Requirements for a clinical electrochemotherapy device-electroporator," Radiol. Oncol., vol. 31, pp. 368-373, 1997.

[32] E. Tekle, R. D. Astumian, and P. B. Chock, "Electroporation by using bipolar oscillating electric field: an improved method for DNA transfection of NIH 3T3 cells," Proc. Nat. Acad. Sci. USA, vol. 88, pp. 4230-4234, 1991.

[33] G. Pucihar, L. M. Mir, and D. Miklavčič, "The effect of pulse repetition frequency on the uptake into electropermeabilized cells in vitro with possible applications in electrochemotherapy," Bioelectrochemistry, vol. 57 , pp. 167-172, 2002
[34] K. C. Melikov, V. A. Frolov, A. Shcherbakov, A. V. Samsonov, Y. A. Chizmadzhev, and L. V. Chernomordik, "Voltage-induced nonconductive pre-pores and metastable single pores in unmodified planar lipid bilayer," Biophys. J., vol. 80, pp. 1829-1836, 2001.

[35] S. Satkauskas, M. F. Bureau, M. Puc, A. Mahfoudi, D. Scherman, D. Miklavčič, and L. M. Mir, "Mechanisms of in vivo DNA electrotransfer: respective contributions of cell electropermeabilization and DNA electrophoresis," Mol. Ther, vol. 5, pp. 133-140, 2002.

[36] G. C. Troiano, K. Stebe, V. Sharma, and L. Tung, "The reduction in electroporation voltages by the addition of a surfactant to planar lipid bilayers," Biophys. J., vol. 75, pp. 880-888, 1998

[37] V. Sharma, K. Stebe, J. C. Murphy, and L. Tung, "Poloxamer 188 decreases susceptibility of artificial lipid membranes to electroporation," Biophys. J., vol. 71, pp. 3229-3241, 1996.

[38] I. G. Abidor, V. B. Arakelyan, L. V. Chernomordik, V. F. Pastushenko, and M. R. Tarasevich, "Electric breakdown of bilayer lipid membranes I. The main experimental facts and their qualitative discussion," Bioelectrochem. Bioenerg., vol. 6, pp. 37-52, 1979.

Alenka Maček Lebar was born in 1967 in Ljubljana, Slovenia. She received the M.Sc. and Ph.D. degrees in electrical engineering from the University of Ljubljana, Ljubljana, Slovenia, in 1995 and 1999, respectively.

She is an Assistant Professor on the Faculty of Electrical Engineering, University of Ljubljana. Her main research is directed toward the biomedical engineering field, especially in the field of electroporation.

Gregory C. Troiano was born in 1974 in Mount Vernon, NY. He received the B.S. and M. Sc. degrees in biomedical engineering with a concentration in chemical engineering from The Johns Hopkins University, Baltimore, MD, in 1996 and 1998 , respectively.

He is with Alkermes Inc., Bostom, MA. His main research interests lie in drug delivery, including electroporation and controlled release.

Leslie Tung received the M.Sc. and Ph.D. degrees in electrical engineering from the Massachusetts Institute of Technology, Cambridge, in 1972 and 1978, respectively.

Since 1993, he has been an Associate Professor of Biomedical Engineering at The Johns Hopkins University, Baltimore, MD. His main research interests are in cardiac electrophysiology, including theoretical modeling and computer simulations, mechanoelectrical coupling, electroporation, and biomedical sensors.

Damijan Miklavčič was born in 1963 in Ljubljana, Slovenia. He received the M.Sc. and Ph.D. degrees in electrical engineering from the University of Ljubljana, Ljubljana, Slovenia

Since 2002, he has been a Professor with the Faculty of Electrical Engineering, University of Ljubljana, and Head of the Laboratory of Biocybernetics. $\mathrm{He}$ works in the field of biomedical engineering. His research interests include electroporation-assisted drug delivery, including cancer treatment by means of electrochemotherapy, tissue oxygenation, and modeling. 